\title{
Medication reconciliation in admission hospitalization: retrospective study
}

\author{
Juliana DORNELES ${ }^{1}$, Calize Olivera dos SANTOS ${ }^{2}$, Lucélia Hernandes LIMA ${ }^{3}$, Carine Raquel BLATT ${ }^{4}$ \\ ${ }^{1}$ Universidade Federal de Ciências da Saúde de Porto Alegre, ${ }^{2}$ Irmandade de Santa Casa de Misericórdia de Porto Alegre, ${ }^{3}$ Irmandade de Santa \\ Casa de Misericórdia de Porto Alegre, ${ }^{4}$ Universidade Federal de Ciências da Saúde de Porto Alegre
}

Corresponding author: Blatt CR, carineblatt@ufcspa.edu.br

Submitted: 25-09-2019 Resubmitted: 18-05-2020 Accepted: 26-05-2020

Peer review: blind reviewers

\begin{abstract}
Objective: to quantify and describe the discrepancies found in medication reconciliation (MR) in patients at hospital admission. Methods: Retrospective study performed from September to November 2018, based on data from the MR of patients at hospital admission of a large hospital in the city of Porto Alegre / RS. MR was shared with nursing (collection of patient's medication history) and pharmacy (comparison of medication list before and during hospitalization). The referred drugs were classify according to the Anatomic Therapeutic Chemical (ATC) classification in their first level and the discrepancies were classify according to intentionality (intentional and unintentional). Results: 81 patients submitted to MR, and $80 \%$ of them had some discrepancy. Of the 328 drugs evaluated, $44.8 \%$ presented discrepancies, totaling 147 discrepancies, being intentional $(n=97)$ and unintentional $(n=50)$. The omission of medication was the most frequent discrepancies (48.3\%). After identify unintencional discrepancies 50\% of drug were included in prescription. Cardiovascular drugs and digestive and metabolism drugs were the groups with the highest frequency of discrepancy. Conclusion: Since $80 \%$ of prescriptions on hospital admission had some discrepancy regarding the use of medication by patients before hospital admission, it is understood the importance of performing MR as a pharmaceutical service and with the objective of increasing patient safety regarding drug therapy.
\end{abstract}

Keywords: medication reconciliation, medication errors, pharmacy service, hospital, pharmaceutical care.

\section{Conciliação medicamentosa na admissão hospitalar: estudo retrospectivo}

\section{Resumo}

Objetivos: quantificar e descrever as discrepâncias encontradas na conciliação medicamentosa (CM) em pacientes na admissão hospitalar. Métodos: Estudo retrospectivo realizado de setembro a novembro de 2018, a partir de dados de CM de prescrições de pacientes na admissão hospitalar de um hospital de grande porte na cidade de Porto Alegre/RS. A CM foi realizada de forma compartilhada com a enfermagem (coleta do histórico de medicamentos do paciente) e pela farmácia (comparação da lista de medicamentos antes e durante internação). Os medicamentos foram classificados de acordo com a classificação Anatomic Therapeutic Chemical (ATC) em seu primeiro nível e as discrepâncias foram classificadas segundo a intencionalidade (intencionais e não intencionais). Resultados: Foi realizada CM de 81 prescrições, sendo que 80\% destas tiveram alguma discrepância. Do total de 328 medicamentos avaliados, 44,8\% apresentaram discrepâncias, totalizando 147 discrepâncias, sendo intencionais $(n=97)$ e não intencionais $(n=50)$. A discrepância mais frequente foi a omissão do medicamento (48,3\%). Após a identificação da discrepância não intencional houve reintrodução do medicamento em $50 \%$ das situações. Os medicamentos que atuam no sistema cardiovascular e no sistema digestivo e metabolismo foram a classe farmacológica com maior frequência de discrepância. Conclusão: Visto que $80 \%$ das prescrições na admissão hospitalar apresentaram alguma discrepância em relação ao uso de medicamentos pelos pacientes prévios a admissão, compreende-se a importância da realização da CM como um serviço farmacêutico e com o objetivo de aumentar a segurança do paciente em relação a terapia medicamentosa.

Palavras-chave: reconciliação medicamentosa, erros de medicação, serviço de farmácia hospitalar, cuidado farmacêutico.

\section{Introduction}

Health institutions increasingly seek to ensure patient safety; however, the path to the effectiveness of this practice in Brazil is still long. The culture of patient safety includes the adoption of preventive measures to anticipate errors. Initially, the activities related to patient safety aimed at measuring the incidence of errors; however, over the years, the need is understood to correct processes in order to reduce preventable adverse events or harms ${ }^{1,2}$. 
In 2013, with the aim of promoting improvements related to patient safety, the National Patient Safety Program (Programa Nacional de Segurança do Paciente, PNSP) was created through ordinance MS/ GM No. 529. It has six protocols, including the improvement of communication among health professionals and of safety in the prescription, use, and administration of medications ${ }^{2}$.

Several international organizations, such as the World Health Organization (WHO), the National Institute for Health and Clinical Excellence (NICE), the Joint Commission on Accreditation of Health Care Organizations (JCAHO), and the Institute for Healthcare Improvement (IHI), consider medication reconciliation (MR) as the key to improving pharmaceutical care ${ }^{3}$. This practice is performed to avoid errors related to medications, as well as to ensure that the added, altered, or discontinued medications are appropriate for patients who have been through different levels of health care or services ${ }^{1,4,5}$. In addition, the performance of MR makes the pharmacist work together with the multidisciplinary team with a view to patient care ${ }^{6,7}$

In Brazil, according to the Federal Pharmacy Council, the definition of medication reconciliation includes the service by which the pharmacist draws up an accurate list of all the drugs (name or formulation, concentration/dynamization, pharmaceutical form, dose, route of administration and frequency of use, duration of treatment) used by the patient, reconciling information from the medical record, prescription, patient, and caregivers, among others. This service is generally provided when the patient travels through different levels of care or through different health services, with the aim of reducing unintentional discrepancies ${ }^{8}$.

Medication reconciliation is a process which involves three stages: 1) collecting information and checking which medications are on the patient's list; 2) confirmation of the prescribed medications and dosages, checking for possible errors and identification of the discrepancies between the medications prescribed at each transition point; 3 ) pharmaceutical intervention together with the prescriber $^{9,10}$.

A systematic review of 83 randomized and non-randomized studies evaluating drug discrepancies and problems related to pharmacotherapy identified in the MR at hospital admission a rate of unintentional discrepancies from $3.4 \%$ to $98.2 \%$, and from 25.0 to $80.0 \%$ at discharge. When assessing the problems related to medications or to possible adverse reactions, the studies signaled rates from $17.2 \%$ to $94.0 \%$. According to the results of this review, MR helps to identify discrepancies and to reduce the medicationrelated harms to the patient ${ }^{5}$.

Discrepancies can be classified as intentional and unintentional. In the intentional ones, the prescriber is aware of the medications used by the patient and deliberately choses to change them, based on the patient's care plan and/or according to the hospital form. The alteration, addition, or discontinuation of the medication was conscious, justified, and documented (disease evolution, prescription, laboratory tests, etc. $)^{1,11}$

In intentional undocumented discrepancies, the prescriber makes the change deliberately; however, it is not documented. The lack of evidence justifying the change can lead to confusion and/or errors for the nursing and pharmacy teams, who need additional clarification to confirm the prescriber's true intention. In unintentional discrepancies, due to lack of knowledge about the drugs the patient used before hospitalization, the prescriber makes an unintentional change, addition, or omission. This type of discrepancy is the most harmful for the patient because it easily leads to adverse effects or to problems related to medications $(\text { PRM })^{1,11}$

Considering medication reconciliation as a tool that brings benefits to patient safety in the medication scope, the objective of this study was to describe and quantify medication reconciliation at hospital admission of patients in a large hospital in the city of Porto Alegre/RS.

\section{Methods}

This is an observational and retrospective study with analysis of the medication reconciliations performed at hospital admission in Irmandade Santa Casa de Misericórdia de Porto Alegre (ISCMPA). The institution implemented the medication reconciliation service where the nursing team is responsible for collecting the medication history at patient's admission, and the pharmacy team is responsible for checking the discrepancies between the drugs used by the patient before hospitalization and at admission. All data is recorded in the patient's electronic medical record, accessible by all the health professionals.

Data was collected and obtained through the TASY ${ }^{\circledR}$ electronic health management system, from the medication reconciliation records in a specific form during the period from September to November 2018. Complementary data needed to assess the intentionality of the discrepancy were searched for in the patients' medical records.

The study included all the patients with a record of medication reconciliation performed at hospital admission. Patients who were admitted to the emergency room and were discharged in less than 24 hours were excluded.

The drugs were classified according to the Anatomic Therapeutic Chemical (ATC) classification in its first level ${ }^{(12)}$ and the discrepancies were classified according to type and intentionality (intentional and unintentional). Unintentional discrepancies were also subclassified by type into: Omission, Duplicity of Drug Therapy, Dose, Frequency, Interval or Route of administration ${ }^{(13)}$.

The team's conduct after the identification by the pharmacist of unintentional discrepancies was classified into: 1) Reintroduction of the medication or equivalent; 2) Adequacy of the medication administration frequency; 3) Adequacy of the medication dose; 4) Non-inclusion of the medication. The team's justification for intentional discrepancies was classified into: 1) Change in the patient's condition; 2) Medical justification; 3) No need for adjustment (sporadic/symptomatic medication); 4) Institutional protocols. The frequency of discrepancies in relation to the number of patients and in relation to the number of medications, as well as the frequency for performing MR per hospital, were calculated.

Data was tabulated using the Excel software, a simple descriptive analysis was performed with presentation by absolute and relative frequency.

The material used for the research consists of retrospective secondary data, so it did not require the Free and Informed Consent Form (FICF). The study was approved by the ISCMPA Ethics Committee under number 833258218.5.0000.5335. 


\section{Results}

The institution's pharmacy service has a pharmacist responsible for the drug information service, which avails standardized manuals and protocols for use by the assistential pharmacists and a pharmacist responsible for registering and for the quality system of the pharmacy service, in which the conducts to be carried out in the different pharmacies of the institution are standardized. At the time of the study, the institution had 8 pharmacists distributed in different hospitals and who developed management and assistential activities.

Medication reconciliation in the hospital under study is performed only at admission and under shared responsibility. The nursing team is responsible for conducting the interview with the patient/ caregiver upon admission and for recording in the patient's health history information regarding the medications used prior to admission. The pharmacists should compare the list inserted in the health history with the patient's prescription at hospital admission and record the discrepancies and the interventions performed in the patient's record.

During the study period (September to November 2018), MRs of 82 patients admitted to the hospital were performed. One patient was excluded from the study because he spent only a few hours under observation in the hospital, totaling 81 patients, 46 of whom were female. The MRs were distributed according to the hospital in Table 1.

Among the 81 prescriptions of the patients included in the study, 65 had at least 1 medication with some kind of discrepancy; thus, $80 \%$ of the patients had some discrepancy in relation to their medications at hospital admission. In total, 328 medications were evaluated and discrepancies were observed in 147. The mean number of prescription medications was 4.04 and the mean number of discrepancies per prescription was 1.81. The discrepancies were classified as intentional $(n=97)$ and unintentional $(n=50)$; in Table 2 it is possible to view this classification according to the first level of the ATC and to the type of discrepancy.

The unintentional discrepancies identified by the pharmacist were presented and discussed with the team and generated the conducts that can be seen in Table 2. The justifications for the intentional discrepancies found in the MR can also be seen in Table 2 .

\section{Discussion}

This study sought to describe the results of the MR service recently implemented by the Pharmacy service at ISCMPA. Although the number of patients included in the study is small when compared to the number of beds in the hospital (more than 1,200 beds), $80 \%$ of the patients had at least one discrepancy in the medications used prior to hospitalization with those used at admission, demonstrating the importance of performing this clinical activity.

Unintentional discrepancies generally have a higher risk of causing harm to the patient ${ }^{18}$; therefore, greater attention must be paid to them and to the medications involved ${ }^{18}$. In our study, unintentional discrepancies represented $34 \%$ of the discrepancies. In addition to medications that act on the cardiovascular system, another group that stood out were those that act on the digestive system and on metabolism. A study with similar findings identified $50 \%$ of discrepancies in both groups and classified them as high risk due to their ability to cause harms to the patient ${ }^{3}$. In a systematic review, 18 studies that categorized the classes of medications involved in the discrepancies identified that 13 of them had the highest frequency of discrepancies involving the medications that act on the cardiovascular system ${ }^{5}$.

The omission of medications can cause harms to the patient related to the non-inclusion of a medication. According to a systematic review, of the MRs performed at the patient's admission, $40 \%$ to $100 \%$ of the discrepancies were classified as drug omission; in addition, the rate of unintentional discrepancies was close to $32 \%$. Another study evaluated the impact of unintentional discrepancies in the prescription of patients in the hospital setting at admission and later; in relation to home medications, $18 \%$ of the patients had at least one discrepancy and $69 \%$ of errors were identified at admission, where the patients are more susceptible to the error involving the medications, due to the non-inclusion of their drug therapy ${ }^{14}$.

When the health service understands the importance of performing MR in order to promote rational use and reduce errors related to medications, the recording of discrepancies in relation to the drug therapy can become an important indicator for the service $^{15}$. When we analyze data from hospitals in European countries like Portugal and Spain, or the United States, we find that the performance of the clinical pharmacist, as well as the MR, is consolidated in most of the hospitals ${ }^{3,5,10,14,18}$. Through various actions, the pharmacist is able to identify and prevent problems related to medications and unnecessary costs, as well as to increase patient safety; however, despite the activities related to clinical pharmacy and its aspects being highlighted internationally, in Brazil this reality is a little more incipient ${ }^{6,17}$.

This study has some limitations: the fact that collection was carried out retrospectively, and the small number of MRs performed. The reduced number of MRs can be associated with the absence of the pharmacist at the bedside, like the rest of the health care professionals, as well as with the fact that the pharmacist's activities are still closely associated with pharmacy management. In addition, the MRs recorded in the system did not have all the information necessary for the data collection proposed in this study. There was also a low rate of registration of the patients' health history.

Table 1. Distribution by hospital of the Medication reconciliations at admission carried out from September to November 2018.

\begin{tabular}{llllllll}
\hline Data & H1 (N=21) & H2 (N=03) & H3 (N=21) & H4 (N=19) & H5 (N=5) & H6 (N=12) & Total (N=81) \\
\hline Female gender $\mathbf{n}(\%)$ & $13(61.9)$ & $2(66.7)$ & $12(57.1)$ & $8(42.1)$ & $4(80.0)$ & $7(58.3)$ & $46(56.8)$ \\
Age (years old) mean (SD) & $3.4(4.2)$ & $59.7(5.0)$ & $59.2(11.3)$ & $67.3(14.2)$ & $52(16.7)$ & $65.7(13.4)$ & $46.9(28.4)$ \\
Medications evaluated $\mathbf{n}(\%)$ & $52(15.8)$ & $14(4.3)$ & $120(36.6)$ & $75(22.9)$ & $13(4.0)$ & $54(16.4)$ & $328(100.0)$ \\
Total discrepancies $\mathbf{n}(\%)$ & $24(16.3)$ & $8(5.4)$ & $46(31.3)$ & $37(25.1)$ & $10(6.8)$ & $22(15.0)$ & $147(100.0)$ \\
Unintentional discrepancies n (\%) & $4(8.0)$ & $6(12.0)$ & $15(30.0)$ & $10(20.0)$ & $4(8.0)$ & $11(22.0)$ & $50(34.0)$ \\
Intentional discrepancies $\mathbf{n}(\%)$ & $20(20.6)$ & $2(2.1)$ & $31(32.0)$ & $27(27.8)$ & $6(6.2)$ & $11(11.3)$ & $97(66.0)$ \\
Mean number of discrepancies per patient (mean; SD) & $1.14(0.91)$ & $2.67(3.79)$ & $2.19(1.72)$ & $1.95(1.99)$ & $2.00(1.00)$ & $1.83(1.53)$ & $1.81(1.66)$ \\
\hline
\end{tabular}

Legend - H1 - Hospital specialized in children; H2 - Hospital specialized in transplants; H3 - General Hospital; H4 - Hospital specialized in cardiology; H5 - Hospital specialized in lung diseases; H6- Hospital specialized in oncology. 
Table 2. Intentional and unintentional discrepancies according to Anatomic Therapeutic Chemical (ATC), identified from the Medication reconciliations at admission carried out in a hospital from September to November 2018

\begin{tabular}{|c|c|c|c|}
\hline Data & $\begin{array}{l}\text { Unintentional } \\
\text { discrepancies } \\
\mathrm{N}=50 \mathrm{n}(\%)\end{array}$ & $\begin{array}{l}\text { Intentional } \\
\text { discrepancies } \\
\mathrm{N}=97 \mathrm{n}(\%)\end{array}$ & $\begin{array}{l}\text { Total discrepancies } \\
\mathrm{N}=147 \\
\mathrm{n}(\%)\end{array}$ \\
\hline \multicolumn{4}{|l|}{ ATC classification of first level medications } \\
\hline A- digestive system and metabolism & $6(12.0)$ & $17(17.5)$ & $23(15.6)$ \\
\hline B- blood and hematopoietic organs & $2(4.0)$ & $8(8.2)$ & $10(6.8)$ \\
\hline C- cardiovascular system & $18(36.0)$ & $30(30.9)$ & $48(32.6)$ \\
\hline G- genito-urinary tract and sex hormones & $2(4.0)$ & - & $2(1.4)$ \\
\hline H- systemic hormonal preparations & $1(2.0)$ & $13(13.4)$ & $14(9.5)$ \\
\hline J- general anti-infectives for systemic use & - & $4(4.1)$ & $4(2.7)$ \\
\hline L- antineoplastic agents and immunomodulators & $7(14.0)$ & $12(12.4)$ & $19(12.9)$ \\
\hline M- musculoskeletal system & $2(4.0)$ & $2(2.1)$ & $4(2.7)$ \\
\hline M- musculoskeletal system & $2(4.0)$ & $1(1.0)$ & $3(2.0)$ \\
\hline $\mathrm{N}$ - central nervous system & $8(16.0)$ & $8(8.2)$ & $16(10.9)$ \\
\hline R- respiratory system & $2(4.0)$ & $2(2.1)$ & $4(2.7)$ \\
\hline \multicolumn{4}{|l|}{ Classification of discrepancies according to subtype } \\
\hline Omission & $31(62.0)$ & $40(41.2)$ & $71(48.3)$ \\
\hline Duplicity & - & $9(9.3)$ & $9(6.1)$ \\
\hline Dose & $9(18.0)$ & $24(24.7)$ & $33(22.4)$ \\
\hline Frequency & $10(20.0)$ & $14(14.4)$ & $24(16.3)$ \\
\hline Route & - & $10(10.3)$ & $10(6.8)$ \\
\hline \multicolumn{4}{|l|}{ Team conduct after the pharmacist identifies unintentional discrepancies } \\
\hline Reintroduction of pre-admission medication or introduction of therapeutic equivalent & $25(50.0)$ & - & - \\
\hline Adequacy of the dose for the pre-admission dose or further dose modification & $6(12.0)$ & - & - \\
\hline $\begin{array}{l}\text { Adequacy of the administration interval for pre-admission interval or new interval } \\
\text { modification }\end{array}$ & 9 (18.0) & - & - \\
\hline Medication not included in the patient's prescription & $10(20.0)$ & - & - \\
\hline \multicolumn{4}{|l|}{ Staff justification for intentional discrepancies } \\
\hline Change in the patient's condition & - & $56(57.7)$ & - \\
\hline Sporadic/Symptomatic medication & - & $13(13.4)$ & - \\
\hline Institutional protocols & - & $12(12.4)$ & - \\
\hline Punctual justification & - & $16(16.5)$ & - \\
\hline
\end{tabular}

In the institution under study, MR is shared with the nursing service, with the nurses being responsible for collecting and recording the patient's health history. The pharmacy service periodically carries out continuing education with the nursing team seeking greater adherence to this activity. However, there is still lack of knowledge on the part of the team about the necessary information and about the importance of this activity.

These limitations are part of the development of studies that use retrospective data obtained from the work processes underway in the establishments, thus verifying the need for continuous improvement in the processes and workflows, which demonstrate how much we need to advance in relation to the clinical pharmacy service and medication reconciliation.

Hospitals that have a computerized system that meets the needs of the multidisciplinary team can increase the accuracy of the documentation used to perform MRs. The use of this computerized support helps in a better health history and reduces errors when transcribing care ${ }^{18,19}$.

The estimated mean time to perform a MR by trained pharmaceutical professionals is approximately 15 minutes, considering that they perform the MR using the patient's health history ${ }^{10}$. This fact shows the great demand that we have for clinical pharmacists because, considering this data, a pharmacist hired for 40 hours per week, if only doing MRs, would be able to perform 160 MRs per week.
Despite this, when the pharmacist collects data from the patient's history, the data may be more accurate. In Saudi Arabia, a study was carried out to compare the acquisition of the MR list, among physicians and pharmacists, where they found $43 \%$ and $17 \%$ of discrepancies, respectively, with $77 \%$ being classified as omission. In addition, the discrepancies were classified as mild, moderate and severe, the last two being the most prevalent ${ }^{20}$.

In the study developed at the academic trauma center of the Oregon Health and Science University (USA), the impact was evaluated of a pharmaceutical intervention program whose objective was to offer information, guidance, and education at discharge in patients with heart failure. 36 patients were evaluated and the results were compared with a control group, the reconciliation measures performed by the pharmacist decreased the rates of hospital readmission in 30 days related to heart failure ${ }^{21}$. In addition, in the systematic review, discrepancies of $3.4 \%$ to $97 \%$ were found at hospital discharge ${ }^{5}$, which justifies the importance of this practice in the hospital services also at the time of discharge.

MR contributes significantly to the pharmacist's clinical practice in order to guarantee continuity of treatment, reducing the risks of errors and harms, and promoting the provision of adequate care to optimize pharmacotherapy ${ }^{22}$. Pharmacists and the clinical pharmacy service are responsible for implementing and improving this service, as well as for recording, monitoring, and disseminating MR data to the health teams. 


\section{Conclusion}

The importance was verified of performing MR in order to ensure patient safety, since $80 \%$ of the patients had some discrepancy in relation to the use of medications at hospital admission. In this way, MR contributes positively to the institution, promoting rational use and reducing errors related to drugs during the transition of care. Considering that the transition of care is always a critical point for the health system, and it becomes even more complex when talking about a large institution, like the one in which this study was carried out, it is identified that the MR performed by the clinical pharmacist can contribute to the achievement of the third global challenge, which is harmless medications, with the increase of the pharmacist's participation in MR at the time of admission.

\section{Funding sources}

The authors declare that the research did not receive funding for its realization.

\section{Collaborators}

JCD participated in the design of the project, data collection and analysis, and writing of the manuscript. COS participated in the critical review of the article. LHL participated in the design of the project and in the critical review of the article. CRB participated in the design of the project, supervision of data collection, and critical writing and review of the article.

\section{Acknowledgments}

We thank the Porto Alegre Federal University of Health Sciences and Irmandade Santa Casa de Misericórdia de Porto Alegre for their participation and support in carrying out this work.

\section{Conflict of interest statement}

The authors declare that there is no conflict of interest in relation to this article.

\section{References}

1. WHO. The High 5s Project Medication Reconciliation Implementation Guide, 78.: Available in http://www.who. int/patientsafety/implementation/solutions/high5s/High5_ InterimReport.pdf. Accessed on: 10 May 2018.

2. Brasil. Ministério da Saúde. Documento de referência para - Programa Nacional de Segurança do Paciente/Ministério da Saúde; Fundação Oswaldo Cruz; Agência Nacional de Vigilância Sanitária. Brasília: Ministério da Saúde; 2013.

3. Bandrés MÁA, Mendoza MA, Nicolás FG, et al. Pharmacist-led medication reconciliation to reduce discrepancies in transitions of care in Spain. Int J Clin Pharm. 2013;35(6):1083-1090.

4. Aspden P, Wolcott J, Bootman JL, et al. Committee on Identifying and Preventing Medication Errors. Preventing medication errors. Quality Chasm Series (Hardcover). Washington: National Academies Press; 2007. Available in: http://perpustakaan. stik-avicenna.ac.id/wp-content/uploads/2014/11/PreventingMedication-Error.pdf. Accessed on May 15, 2018.
5. Lehnbom EC, Stewart MJ, Manias E, et al. Impact of medication reconciliation and review on clinical outcomes. Annals of Pharmacotherapy. 2014;48(10):1298-1312.

6. Lindenmeyer LP, Goulart VP, Hegele V. Conciliação medicamentosa como estratégia para a segurança do paciente oncológico. Rev. Bras. Farm. General Serv. Saúde. 2013; 4(4):51-55.

7. Schuch AZ, Zuckermann J, Santos MLF, et al. Reconciliação de medicamentos na admissão em uma unidade de oncologia pediátrica. Rev. Bras. Farm. General Serv. Saúde. 2013;4(2):35-39.

8. Conselho Federal de Farmácia. Serviços farmacêuticos diretamente destinados ao paciente, à família e à comunidade: contextualização e arcabouço conceitual. Brasília: Conselho Federal de Farmácia, 2016.

9. Institute for Healthcare Improvement. 5 Million Lives Campaign. How-to guide: prevent adverse drug events (medication reconciliation). Mar 2014 Available in:http://www.ihi.org/resources/Pages/Tools/\%20 HowtoGuidePreventAdverseDrugEvents.aspx. Accessed on June 11, 2018.

10. Vira T, Colquhoun M, \& Etchells E. Reconcilable differences: correcting medication errors at hospital admission and discharge. BMJ Quality \& Safety. 2006;15(2):122-126.

11. Brito $A M G$ de. Reconciliação e revisão da medicação na unidade de hospitalização domiciliária. Tese de Doutorado. 2017. Available in:https://comum.rcaap. pt/bitstream/10400.26/20189/1/Brito_Ana_Mafalda Greg\%c3\%b3rio_de.pdf. Accessed on May 20, 2018. 51-5.

12. WHO. Anatomical Therapeutic Chemical Classification (ATC), 2015. Available in: http://www.whocc.no/atc/structure_and_ principles/. Accessed on: April 16, 2019.

13. Lombardi NF, Mendes AEM, Lucchetta RC, et al. Analysis of the discrepancies identified during medication reconciliation on patient admission in cardiology units: a descriptive study. Revista latino-americana de enfermagem. 2016;24:e2760.

14. Pourrat $X$, Corneau H, Floch $S$, et al. Communication between community and hospital pharmacists: impact on medication reconciliation at admission. Int J Clin Pharm. 2013;35(4):656663.

15. Tonello ML, Alves SP, de Azevedo Frank, M, et al. Discrepâncias entre os registros de prontuário acerca da farmacoterapia de pacientes pediátricos com fibrose cística. Clin Biomed Res. 2017;37(3):181-186.

16. Miranda LD, Cavalcante AL, Silva EV, et al. Reconciliation of medications upon the admission of patients to the cardiology sector of a university hospital. Rev Bras Farm Hosp Serv Saude. 2019 Oct-Dec;10(4):0353.

17. Aguiar KDS, Santos JMD, Cambrussi MC, et al. Segurança do paciente e o valor da intervenção farmacêutica em um hospital oncológico. Einstein (São Paulo). 2018;16(1):eAO4122.

18. 18 Mekonnen AB, Abebe TB, McLachlan AJ, et al. Impact of electronic medication reconciliation interventions on medication discrepancies at hospital transitions: a systematic review and meta-analysis. BMC Med Inform Decis Mak. 2016;16(1):112. 
19. Santos COD, Lazaretto FZ, Lima LH, et al. Reconciliação de medicamentos: processo de implantação em um complexo hospitalar com a utilização de sistema eletrônico. Saúde em Debate. 2019;43:368-377.

20. Abdulghani KH, Aseeri MA, Mahmoud A, et al. The impact of pharmacist-led medication reconciliation during admission at tertiary care hospital. Int J Clin Pharm. 2018;40(1):196-201.

21. Warden BA, Freels JP, Furuno JP, et al. Pharmacy-managed program for providing education and discharge instructions for patients with heart failure. Am J Health Syst Pharm. 2014;71(2):134-139.

22. National Prescription Center. Medicines reconciliation - a guide to implementation. Available in: https://www.nicpld.org/ courses/fp/assets/MM/NPCMedicinesRecGuidelmplementatio. Accessed on: June 11, 2018. 